\title{
Micro Underpinning for In-Service Philosophy: A Case of the Vhembe District Physical Science Teachers
}

\author{
Awelani V. Mudau \\ Department of Science and Technology Education, \\ University of South Africa, South Africa \\ mudauav@unisa.ac.za
}

\section{Doi:10.5901/mjss.2014.v5n10p404}

\begin{abstract}
This paper reports on teachers from 10 schools that performed poorly in the national senior certificate physical science in some circuits of the Vhembe district in the Limpopo province. The focus was on their views on why learners perform poorly. 17 teachers participated in the study which is part of a larger study which aims to develop an intervention strategy to assist these schools and their teachers. The methodological approach was informed by the interpretivist paradigm with a qualitative approach. Participants responded to open ended questionnaires and thereafter were interviewed. The findings indicate that teachers are blaming the lack of support from the district and circuits as well as the learners. The assertions by the teachers should be helpful in designing an intervention strategy and in-service training for these teachers and their learners which should improve the performance in physical science in their schools sustainably.
\end{abstract}

Keywords: performance, intervention strategy, matric, in-service training.

\section{Introduction}

"The unsaid? About 48000 fewer learners wrote physical science in 2013 than in 2009" (Mcfarlane, 2014, p6). This is the reality of the pass rate in Physical science which was $67.4 \%$ in 2013 and $61.3 \%$ in 2012. Hence, even though there was an increase in the pass rate, there was also an inference that fewer students are taking the subject. This resonates well with Spaull (2014) who indicated that there were a cognisance number of students who drop out at grade 10 and 11. An implication of this is that even though the statistics are showing that in general there is an improvement in the pass rate, there are still issues about those that passed with low levels and those that did not get an opportunity to study grade 12. Moreover, Macfarlane (2014) indicate that Umalusi said that the majority of learners still perform at lower levels in Physical science. The majority in this case were those coming from the poor socio economic status background. In fact it is also important to note that only $25.6 \%$ of the learners who wrote Physical science in 2013 passed with $50 \%$ and more (Van der Merwe and Masondo, 2014). This was the lowest percentage in all the national senior certificate examination subjects. Many learners are also channelled into taking senior certificate as part-time candidates so that their results are not included in the national pass rates (Mcfarlane, 2014). Therefore, it does necessitate a continuous need for research on the performances in the national senior certificate and Physical science in particular either to improve it or maintain or increase the quality of the performances.

Studies have been done (Makgato and Mji, 2006 \& Legotlo, Maaga and Sebego, 2006) on the performances of students on physical sciences. These studies showed that the performance of learners is influenced by various factors directly and indirectly. For example, teaching strategies, teacher knowledge, educator discipline and parental involvement. The aspect of teacher knowledge was further emphasised by Ramnarain and Fortus (2013) who showed that the perception of teachers on the introduction of the new topics in the revised curriculum including grade 12 does pose uncertainty with regard to content knowledge and pedagogical knowledge of the new topics. However, it is important to acknowledge as shown by the performances in the 2013 examinations that even though some critics indicate that the examination has been watered down, it has improved significantly.

The study by Mutshaeni (2008) has shown that students from the Vhembe district of the Limpopo province perform better than students in the other regions of the province. The same feat was repeated in 2013 with the region taking first position in the province in the overall national senior certificate results. Yet, there are some schools in the region whose performance does not positively mirror that of most schools in the district. With closer analysis of the results it was found that the performance was hindered by the learner's performance in subject like Physical science. Poor performances in 
Physical science do not advance the aims and goals of the government which are to have learners take carriers in the STEM areas. Hence even though a district like Vhembe is performing, it is important that the overall performance in Physical science also improve in the non-performing schools.

A project was established at the University of South Africa (UNISA) to develop interventional strategies that will help those schools that had poor performances in Physical science. The first phase of the project was to determine the needs analysis so that a tailor made intervention strategy which suits the identified schools is developed. Therefore, the project's objectives were to improve the quality of teaching and learning physical science, provide a base from which to increase the impact of existing programmes and ensuring greater partnership within participating schools. This was to avoid what Jita (2006) calls an impervious lack of micro foundations for in-service training. Furthermore, it was to dispel the one size fits all kind of intervention strategies (Mudau, 2013). Therefore, the purpose of this paper is to report on the views of the teachers regarding poor learner performance in physical science in some schools of the Vhembe district.

\section{Methodology of Research}

10 schools were identified based on their previous year's grade 11 and 12 results in the Vhembe district. Vhembe district is found in the most northern part of the Limpopo province in South Africa. From these schools, 17 teachers participated. Five of the teachers were females and the rest were males. 16 of the teachers' ages were above 40 with only one whose age was 26. Most of the teachers had more than one diploma or certificate or degree. One of the teachers (T13) who participated in the study taught in a performing school and the school's physical science results were also good as they were above $70 \%$. The rationale for including a teacher from a performing school was to get a view on what he does as well as the school so that the results are better. The teacher and the school were chosen on the basis that they were in close proximity to one of the poor performing school. So we thought that results from this school may share something that will help us in comprehending the views from the other teachers.

It was also our perspective that we do not want to re-invent the will on factors that have already been discussed for example by among others by Mji and Makgato (2006). To achieve this, in our discussion, we drew conclusions based on what the teachers said in the questionnaires with what they indicated during interviews. This was to so make a holistic informed fundamental resource on the kind of intervention needed. All the seventeen teachers were given an open ended questionnaire to complete. The teachers were then interviewed using semi structured interviews. Even though the questionnaire of open ended nature was used, the aim was not to quantify responses from those questionnaires but to understand their views. Hence the study is qualitative in nature embedded in an interpretative paradigm. Data from the questionnaires was useful in comparing it with what the teachers views were with regard to the performance of students in grade 12. The interpretation of data for meaning was reached by two processes (Hitchcock \& Hughes, 1995) namely: direct interpretations of the individual instances and/or aggregation of instances where in an

\section{Results}

1 Focus on teacher confidence in teaching the subject, the language of teaching, classroom practices, resources, teaching preparation and in-service training received.

Table 1 captures the teachers ages, No. of learners in the Physical science grade 12 class as well as their qualifications.

Table 1: Teachers' biographical information

\begin{tabular}{|c|c|c|c|}
\hline No & Age \& gender & Teaching Experience, No. of learners & Qualification (s) \\
\hline T1 & F-26 & $1(10)$ & B.Ed. \\
\hline T2 & F-47 & $25(10)$ & STD \& ACE \\
\hline T3 & F-46 & $20(12)$ & BA, B.Ed., Hons \\
\hline T4 & M-50 & $21(5)$ & STD \\
\hline T5 & M-48 & $21(4)$ & BSc, BSc Hons, UED \\
\hline T6 & M-38 & $4(14)$ & BSc, PGCE \\
\hline T7 & M-51 & $26(9)$ & STD,ACE \\
\hline T8 & M-46 & $25(22)$ & STD,ACE \\
\hline T9 & F-40 & $10(16)$ & STD,ACE \\
\hline T10 & M (40) & $21(6)$ & B.A (ED), BA Hons,M.Dev \\
\hline
\end{tabular}




\begin{tabular}{|c|c|c|c|}
\hline T11 & F -40 & $21(79)$ & STD, \\
\hline T12 & M -40 & $21(36)$ & STD \\
\hline T13 & M-40 & $16(64)$ & STD, FDE, BEd \\
\hline T14 & M-581 & $26(10)$ & JSTC, BA \\
\hline T15 & M-49 & $15(20)$ & STD, ACE \\
\hline T16 & M-57 & $2(25)$ & STD, FED \\
\hline T17 & M-43 & $20(35)$ & STD,FED,BEd (Hons) \\
\hline
\end{tabular}

All the participants indicated that they are confident in teaching the subject matter. That is they do not have problems with teaching the subject. All the teachers except four teachers (T1, T11, T12 and T13) indicated that they teach in English but usually use Tshivenda to explain some concepts. T5 indicated that" I usually use Tshivenda as it makes them improve and understand better...". Furthermore T9 showed that "these students are poor in English language so what is the use of only teaching in English...". The four teachers who indicated that they use English only for teaching said they do that because the examinations are in English. Most teachers indicated that they spend about 25\% of the time talking in the classroom. However, some teachers indicated that they talk about $75 \%$ of the time in the classroom. T5 said that" sometimes this learners do not want to say anything and I have to always talk as they waste time...". All the teachers conceded that they spend time drilling the learners in how to respond to questions. Even the teacher from the schools that had a good performance also indicated the same " ... I finish the syllabus in March and then I increase my drilling of the students...".

Most teachers also indicated that they give students homework a minimum of four times a week. T8 indicated that "... only $40 \%$ of the learners do the homework each day...". A similar assertion was shared by other teachers. 16 teachers indicated that they do not have other teaching resources besides the chalkboard and. Only the teacher from the performing school indicated that even though their resources are not sufficient he still use them. He said that "sometimes I bring my mirrors from home and use them when teaching refraction and reflection and it also encourage learners that science is normal as I am using normal mirrors...". They also indicated that they do not have enough furniture for their students as well as textbooks. T4 indicated that they are sometimes called for meetings and all they talk about is the number and example of assessment task that are to be done for the CASS mark. The same assertion was indicated by other participants.

2 Focus on why students do not perform in their schools

One curriculum advisor for a number of circuits/ lack of support from the district/ no in-service trainings (refresher courses)/ big classes.

Most of the teachers indicated that learners are not performing because there is no support from the district. For example, they have only subject adviser who services a number of circuits. Even the principal of one of the schools who is a grade 12 physical science teacher indicated that it is very frustrating for the teachers when they want assistance from the circuit and it is not available. He further indicated that it is not because the adviser is not interested but rather he is inundated with lot of responsibilities. Yet, this point was surprising in that one of the performing schools which is neighbouring one of the non-performing school indicated that they do not have a problem with the assistance from the circuit office as well as the advisors. Some teachers also indicate that there are no quality "refresher courses (T14)". So without the quality or focused in-service training they are left on their own to help leaners even when there are some aspects which they do not understand. Teachers also said that the lack of resources for science practical work negatively affects the teaching and learning of the subject and the performance of learners. T13 also indicated that "my classes are usually too big and I do not give them attention but just talk to them because I cannot give others attention and leave the rest".

No qualified science teachers/ affected by the student roll/ educators moving to greener pastures and other performing schools/ volunteer teachers/ good teachers not interested in rural schools/ lack of quality teachers.

Some teachers indicated that learners are not performing because they are not well qualified teachers. " in our school we have a teacher teaching grade 12 who only did science at grade 12 himself... what do you expect?" one of the teachers indicated talking about his colleague. Some indicted that well qualified teachers leave rural schools for better performing schools or for greener pastures hence only teachers who are volunteering to teach the subject are roped in to try and assist. The volunteer teacher in T11 School was a drop-out from the university. T15 indicated "... the subject is difficult even for me and without the subject adviser support there is nothing I can do...". Whilst T16 said "I passed my teaching qualification many years ago (it was 26 years ago) and since then I just did a course in management and not content based. I have rusted but I still have to teach because there is no one to teach. The circuit will not bring in new teachers cos we have few learners...". 
Learners not disciplined/ fear of subject/ underprepared learners/ learners not doing their homework

Most of the teacher blamed the learners for the poor performance. They indicated that learners are not disciplined and some do not come to school whilst the support from parents is minimal. Due to lack of discipline, some teachers indicated that some learners do not do their homework regularly and only copy it from their fellow students during the first period. Some teachers indicated that leaners are afraid of the subject hence they do not perform. Some teachers indicated that learners do not perform because they struggle with the language (English). They also indicated that because learners do not understand the language they also struggle in comprehending concepts during the class as well as during the examination. The teacher from the performing school indicated that they do not speak any other language in their classrooms besides English from grade 8. He said this ensures that learners are used to the language of teaching.

\section{Discussion}

As already stated it was important that the kind of in-service training or intervention programme designed by the UNISA community engagement project is based on informed resources. This was important to avoid a one size fits all kind of inservice training and intervention strategy (Mudau, 2013). Even though the researcher did not visit the classroom of the teacher we felt that what we found from questionnaires and interviews should be sufficient to assist us in achieving the project's aims. Teachers indicated that learners are not performing because of the circuit and in particular the subject advisor. They blamed the circuit that it is not supporting them in terms of resources as well as lack of focused in-service training. The lack of focused in-service training has been raised by researchers for example Jita (2006) and Mudau (2013). So in this aspect their concern is justifiable even though as to what extent it was going to influence their results is a matter for further research.

Furthermore, they also blamed learners that they are not disciplined as they do not do their homework. Moreover, teachers said that the learners they receive in grade 12 are ill prepared for the class and they are expected to perform miracles with them. This aspect cannot be very correct to all the teachers as most of them also taught the students at grade 11. Hence, the teachers themselves were to blame for the ill preparedness of their learners. Even though the teachers in the questionnaires most of them seemed to be well qualified, the researcher realised that some of them were qualified in other fields than science. Therefore most of them would not have gone through a rigorous learning of the physical science subject content. This is not too surprising even for those whose major was physical science in their secondary teachers' diplomas. This is so because Rollnick, Bennett, Dharsey and Ndlovu (2008) indicated that teachers from the former colleges of education were taught content knowledge which was no more than that of grade 12 . Hence they should be expected to have deficiencies in their teacher knowledge (Mudau, 2013) if the findings of the study by Ramnarain (2013) are to be taken into cognisance.

Based on the fact that most teachers were not fully qualified for the subjects it was logical that others indicated that the subject is difficult even though on the questionnaire they had indicated that they are confident to tech it. So they were just misrepresenting themselves. It is also important for the purposes of the project to note that most of them emphasised drilling which does not encourage comprehension of concepts (Mudau, 2013). So when the lack of comprehension is manifested in the examinations it should not be peculiar, it should be expected. Yet, even the teacher from the performing school also emphasised that they complete the syllabus in March so that they can focus on drilling students and it works for them. Finally, the aspect of lack of resources raised by the teachers cannot be a view to be taken beyond what it says as it is common in South African schools. Moreover there are many under sourced schools in South Africa that are performing.

\section{Conclusions}

It was the aim of the paper to understand the views of the teachers on poor leaners performance in physical science so that a tailored made intervention and in-service training can be designed. As such in the discussion it is clear that the teachers' views on poor learner performance are intertwined with how they teach, what learners do and the external support. Henceforth, the intervention strategy should focus on equipping the teachers with relevant subject matter so that they are confident to teach the subject. That can be done by grouping the identified schools and facilitating the learning of relevant science concepts by teachers in a safe environment. By safe environment we mean where they cannot be labelled as non performing teachers. This should also help those teachers who completed their qualifications a long time ago and did not engage in further studies. It is also imperative that micro kits are given to these schools to enhance their confidence of teaching the subject. However it will also be important that they are trained on how to use the micro kits. 
Whilst the intervention or in-service training is going on, their leaners can be clustered and the learning of identified concepts can be facilitated by experts. As English is also the language of learning, it should also be developed. This can be done by incorporating experts when implementing the intervention strategy for learners. A call should also be made to the government to strategize and find ways of providing human resources for key subjects irrespective of the roll of learners in that school. Avenues for further research on this cohort could be to monitor their classroom practices in terms of teacher knowledge, interactions and discourse using the Classroom Practice Diagnostic Framework (Mudau, 2013). This could be useful in making sure that they are able to sustain themselves after the project has reached its life span. What this paper attempted to portray can also be extended to other circuits, districts which have similar type of problem. We also hope that this paper has increased the micro-resources for in-service training.

\section{Acknowledgements}

I acknowledge Prof M W Lumadi who is the project leader, Dr Taole, Dr V A Nkonyane and other Vhembe intervention project members who were part of the researchers who collected Data.

\section{References}

Legotlo, M. W., Maaga, M. P., and Sebego, M. G. (2006). Perceptions of stakeholders on causes of poor performance in Grade 12 in a province in South Africa. South African Journal of Education, 22(2), 113-118.

Macfarlane, D. (2014). Reading into gaps of Motshekga's script is revealing. Mail and Guardian January 10-16, 6.

Makgato, M., and Mji, A. (2006). Factors associated with high school learners' poor performance: a spotlight on mathematics and physical science. South African journal of education, 26(2), 253-266.

Mudau, A. V. (2013). Teaching Difficulties from Interactions and Discourse in a Science Classroom. Journal of Educational and Social Research, 3(3), 113.

Mutshaeni, H. N. (2008). An analysis of factors influencing Grade 12 results (Doctoral dissertation, University of Pretoria).

Ramnarain, U and Fortus, D. (2013). South African physical sciences teachers' perceptions of new content in a revised curriculum. South African journal of education, 33(1), 1-15.

Ramnarain, U. (2013). The achievement goal orientation of disadvantaged physical sciences students from South Africa. Journal of Baltic Science Education, 12(2).

Rollnick, M., Bennett, J., Dharsey, N. and Ndlovu, T. (2008). The place of subject matter knowledge in pedagogical content: a case study of South African teachers teaching the amount of substance and chemical equilibrium. International Journal of Science Education, 30(10), 1365-1387.

Spaull, N. (2014). Matric is failing SA's lost children. Mail and Guardian January 10-16, 32.

Van der Merwe, J. and Masondo, S. (2014). Insight: Matric results. City Press January 12, 7. 